\title{
Erratum to: Effect of Microwave Radiation on the Solvent-Free Synthesis of MOF-199
}

\author{
A. I. Kudelin ${ }^{a, b, *}$ \\ ${ }^{a}$ Department of Chemistry, Moscow State University, Moscow, 119992 Russia \\ ${ }^{b}$ Zelinsky Institute of Organic Chemistry, Russian Academy of Sciences, Moscow, 119991 Russia \\ *e-mail:a.kudelin@general.chem.msu.ru \\ Received December 19, 2018; revised December 19, 2018; accepted December 19, 2018
}

DOI: $10.1134 / \mathrm{S} 0036024419140012$

The name of the author should read A. I. Kudelin.

The original article can be found online at https://doi.org/10.1134/S0036024418120257 